\title{
SNOW AND ICE STUDIES BY THEMATIC MAPPER AND MULTISPECTRAL SCANNER LANDSAT IMAGES
}

\author{
by
}

Olav Orheim

(Norsk Polarinstitutt, P.O. Box 158, 1330 Oslo Lufthavn, Norway)

and

Baerbel K. Lucchitta

(U.S. Geological Survey, 2255 North Gemini Drive, Flagstaff, AZ 86001, U.S.A.)

\begin{abstract}
Digitally enhanced Landsat Thematic Mapper (TM) images of Antarctica reveal snow and ice features to a detail never seen before in satellite images. The six TM reflective spectral bands have a nominal spatial resolution of $30 \mathrm{~m}$, compared to $80 \mathrm{~m}$ for the Multispectral Scanner (MSS). TM bands $2-4$ are similar to the MSS bands. TM infra-red bands 5 and 7 discriminate better between clouds and snow than MSS or the lower TM bands. They also reveal snow features related to grain-size and possibly other snow properties. These features are not observed in the visible wavelengths. Large features such as flow lines show best in the MSS and lower TM bands. Their visibility is due to photometric effects on slopes. TM thermal band 6 has a resolution of $120 \mathrm{~m}$. It shows ground radiation temperatures and may serve to detect liquid water and to discriminate between features having similar reflectivities in the other bands, such as blue ice.

Repeated Landsat images can be used for sophisticated glaciological studies. By comparing images from 1975 and 1985, flow rates averaging $0.72 \mathrm{~km} \mathrm{a}^{-1}$, and mean longitudinal and transverse strains of respectively $1.3 \times$ $10^{-4} \mathrm{a}^{-1}$ and $130 \times 10^{-4} \mathrm{a}^{-1}$ have been measured for Jutulstraumen, Dronning Maud Land.
\end{abstract}

\section{INTRODUCTION}

The launch of the Landsat satellite series, beginning in 1972, provided a new instrument for glaciological studies which has proved especially valuable in remote areas. Thus Landsat 1, 2, and 3 provided MSS (Multispectral Scanner) coverage of Antarctica (north of the satellite limit at lat. $81^{\circ} \mathrm{S}$.). These images have four spectral band passes with a nominal spatial resolution (pixel size) of about $80 \mathrm{~m}$. Because they have various internal distortions caused by roll, pitch, and yaw of the spacecraft during picture acquisition, it is difficult to produce controlled rectified maps even from the digital data unless a large number of fixed ground-control points are available for geometric corrections (Ødegaard and Helle 1982).

Further images of Antarctica were obtained by Landsat 4 and 5. These include both MSS and TM (Thematic Mapper) images. The latter have additional spectral bands and a spatial resolution of about $30 \mathrm{~m}$; they also have a thermal band which has a resolution of $120 \mathrm{~m}$. Landsat 4 and 5 images are of high quality geometrically and can be placed into map projections with fewer ground-control points.

The first glaciological studies of MSS data tended to work with standard photographic products. Digital analyses, including enhancement techniques, have become more common in recent years and are used for this report.

This paper presents, we believe, the first analyses of TM data of Antarctica (or of any other large ice mass), and discusses features displayed in different TM bands. The data from TM are much more useful than those from MSS, not only because of the three times higher resolution, but also because the expanded spectral range gives additional information. Because the Landsat systems may be unfamiliar to some readers we preface our discussion with some general comments. The paper further compares overlapping images acquired in 1975 and 1985, notes various transient and stationary features of the Jutulstraumen area, and presents values of flow rates and longitudinal and transverse strains (Fig.1).

\section{THE LANDSAT DATA SETS}

Hundreds of images of Antarctica were obtained by Landsat 1, 2, and 3. A nearly complete coverage of the northern part of Dronning [Queen] Maud Land was obtained as a result of NASA project 28550 (Orheim, principal investigator). This project generated 67 scenes, which were mostly collected in the 1975-76 season, and which have relatively low cloud cover. Various unenhanced photographic prints of those scenes were investigated (Orheim 1978). Recently, the US Geological Survey acquired about 170 computer-compatible tapes (CCTs) of the early Landsat MSS images, including some of Dronning Maud Land (Lucchitta and others 1985). One of these scenes, Landsat 2 No. 2281-07424 recorded on 30 October 1975, is discussed here.

Fifty-seven images from central and western Dronning Maud Land were acquired in early 1985 by Landsat 5 . Most of these were recorded both by the MSS and TM systems, and most have low cloud cover. These scenes were requested by Norsk Polarinstitutt, which carried out a simultaneous dedicated ground programme in connection with the Norwegian Antarctic Research Expedition (NARE) 1984-85.

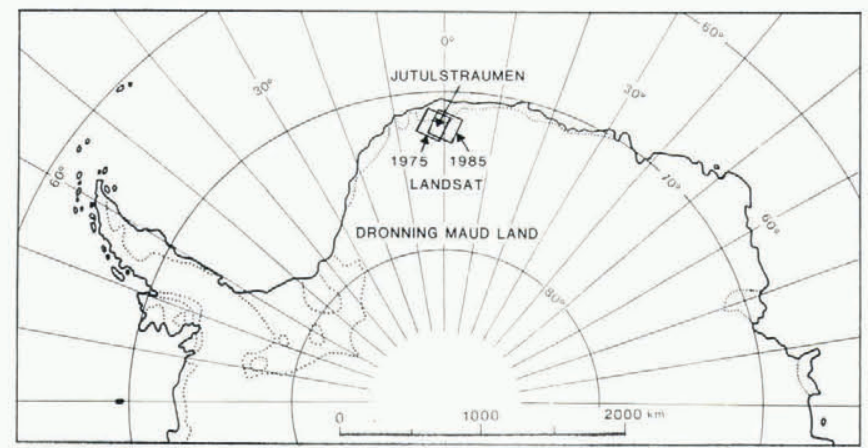

Fig.1. Index map, showing the location of the study area and images. 
A survey team determined geographical coordinates of points - such as small isolated nunataks - that were especially selected to be readily identified on Landsat images. Some of the CCTs of these images have been bought by Norsk Polarinstitutt and are being used in the production of new maps. One scene, No. 5034407520, recorded on 8 February 1985 , is discussed in this article.

\section{DATA PROCESSING AND DIGITAL ENHANCEMENT}

The present study was conducted with digitally enhanced images. The TM data set for one scene comprises 12 CCTs, compared to two CCTs for the MSS set. For this reason, the TM data are divided into four quadrants, numbered $1,2,4$, and 3 reading clockwise from the upper left quadrant. Image processing for the Landsat 2 MSS scene included routine procedures such as radiometric corrections, noise and striping removal, and standard geometric corrections. Further processing included haze removal and linear stretching. For Landsat 5, some routine procedures were already incorporated in purchased CCTs.

Linear stretches were applied to individual TM and MSS bands after inspection of grey-value histograms. Special stretches, and in places filters, were applied to bring out detail in snow and ice. Stretches in TM bands 5 and 7 may be severe because most of the data are concentrated at the lower end of the grey scale. Therefore, TM bands 5 and 7 images appear to have degraded resolution when compared to images of TM bands 1-4 (compare Figs 3 and 6). Grey values and colours may not match across adjacent quadrants within one scene, because different stretches were applied.

Most TM bands have a better dynamic range than those of MSS, so that saturation over snow-covered scenes is less severe. We find that saturation chiefly affects TM band 1, which agrees with the observations of Dozier (1985). Because of the limited information provided by TM band 1 , it is not discussed in this article.

\section{IMAGE INTERPRETATION}

\section{General remarks}

As is shown in Table $I$, the MSS and TM reflective bands have partly overlapping wavelengths. TM bands 2, 3, and 4 have approximately the same wavelengths as MSS bands 4,5 , and 7 (1, 2, and 4 of Landsat 4 and 5).

The basic physics of remote sensing of snow and ice in the MSS and TM bands are well established. The spectral reflectivity of snow depends on grain-size and shape, near-surface liquid water content, depth and surface roughness, impurities, and angle of solar incidence. Various models have been developed to calculate changes in snow reflectivity (e.g. Colwell 1983, chapter 3), and it was found that the reflectivity generally decreases with increasing wavelength in the visual and near infra-red, and that the variations with wavelength of albedo of snow, firn, and ice are broadly parallel (Qunzhu and others 1984).

The snow albedo decreases with increasing grain-size at wavelengths above $0.7 \mu \mathrm{m}$ (TM bands 4,5 , and 7 ), but it is little affected by grain-size in shorter wavelengths (TM bands 1-3) (Choudhury and Chang 1981). Thus grain-size variations do not show in the lower MSS or TM bands. The
MSS bands also do not discriminate well between snow and clouds, because snow and clouds both reflect highly at MSS wavelengths. TM bands 5 and 7 , on the other hand, discriminate well between snow, ice clouds, and water clouds, which have increasingly higher albedos, in that order (Dozier 1985). Therefore, snow will appear darker than clouds in the reflective infra-red bands.

The total emitted thermal radiation is given by: $\mathrm{R}=$ $\epsilon \sigma \mathrm{T}^{4}$, where $\epsilon$ is the emissivity, $\sigma$ the Stefan-Boltzmann constant, and $\mathrm{T}$ the absolute temperature. The thermal radiation of snow is affected by temperature, crystal size, and liquid-water content (Hall and Martinec 1985). The radiation at terrestrial temperatures is strongest between 9 and $14 \mu \mathrm{m}$, with a maximum around $11 \mu \mathrm{m}$ at temperatures in the $-25^{\circ}$ to $0^{\circ} \mathrm{C}$ range. This maximum is covered by TM band 6, whose spectral band path also lies in an atmospheric window of transparency to water vapour, so that the band records the ground temperatures. No radiation occurs at the above temperatures in the range of the TM reflective bands.

The following presents some examples of the information available from the TM data. In some cases the interpretations seem well established. In others the full understanding of the phenomena shown by the TM images requires ground confirmation that is not presently available. We find that understanding is increased by studying the separate images of individual bands in addition to the colour composites.

\section{TM bands $2-4$}

These bands are most easily interpreted, as they are similar to the familiar MSS bands, for which interpretations were verified on the ground. Comparison of TM and corresponding MSS images shows that these are indeed similar, except for the higher resolution of TM. The similarity is illustrated by Figs 2 and 3, which show composites of MSS bands 1,2 , and 4 (4, 5, and 7) and TM bands 2,3 , and 4 of the same scene. It is well established that among MSS bands, band 4 (7) gives the greatest information for snow and ice, both because band 4 (7) lacks saturation, and because it shows good contrast in snow and ice. The same applies to TM band 4 .

The three times higher resolution of TM compared to MSS represents a major advance in our ability to detect small snow and ice features. Enhanced TM images can be produced at a scale of $1: 100000$ without unacceptable degradation caused by the pixel size. Typically, a scale of $1: 250000$ is the maximum acceptable magnification for MSS images. A picture comparison is given in Fig.4, which shows the shear rifts along the east side of Jutulstraumen. Fig.4a and b show that an enlargement to $1: 100000$ results in unacceptable quality for the MSS image but good quality for the TM image. Fig.4c shows, for comparison, the most recent oblique aerial photograph of the area available to us. The activity in this fractured area is so intense that no common features are visible in the TM image and the photograph taken 26 years earlier.

We have determined the depths of various rifts in the TM image from trigonometric relations between shadow lengths and Sun angle. Most shadows measure 1-3 pixels, corresponding to depths of $10-30 \mathrm{~m}$; the floors of the

\section{TABLE I}

\begin{tabular}{lclccl} 
MSS band* & $\begin{array}{c}\text { Wavelength } \\
\mu \mathrm{m}\end{array}$ & Region & TM band & $\begin{array}{c}\text { Wavelength } \\
\mu \mathrm{m}\end{array}$ & \multicolumn{2}{c}{$\begin{array}{l}\text { Region } \\
\end{array}$} \\
& & & & & \\
4 or 1 & $0.5-0.6$ & green-yellow & 1 & $0.45-0.52$ & blue-green \\
5 or 2 & $0.6-0.7$ & red & 2 & $0.52-0.60$ & green-yellow \\
6 or 3 & $0.7-0.8$ & "near" infra-red & 3 & $0.63-0.69$ & red \\
7 or 4 & $0.8-1.1$ & "near" infra-red & 4 & $0.76-0.90$ & "near" infra-red \\
& & & 5 & $1.55-1.75$ & "middle" infra-red \\
& & & 6 & $10.40-12.50$ & thermal \\
& & & 7 & $2.08-2.35$ & "middle" infra-red
\end{tabular}

*The MSS bands were numbered 4-7 for Landsat 1-3, and 1-4 for Landsat 4 and 5 . In this article we use 4-7 for the Landsat 2 image, and 1-4 for the Landsat 5 image. (Band labels for the respective alternate system are shown in parentheses for clarity.) 


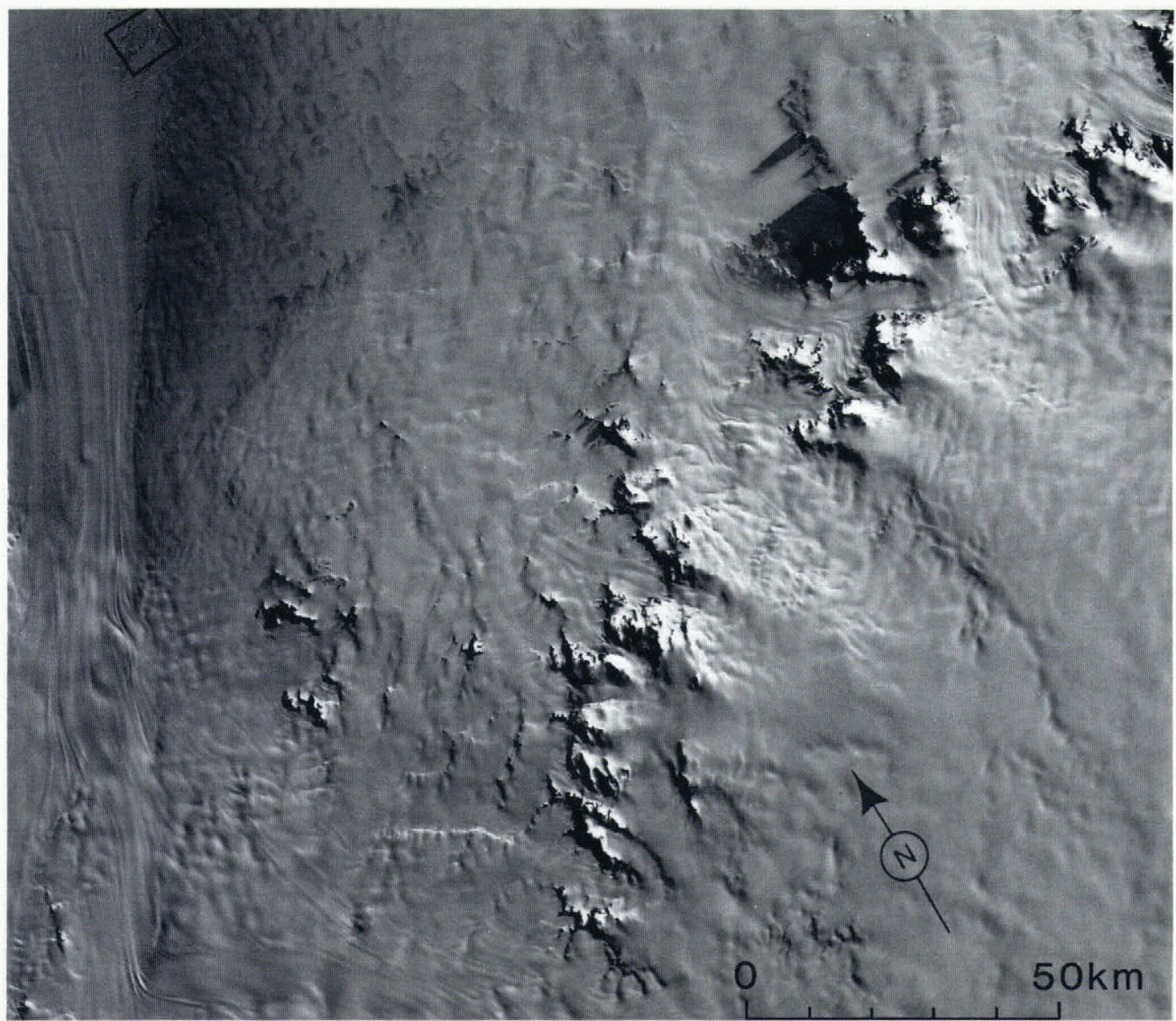

$\uparrow$ Fig.2. Composite image of MSS bands 1, 2, and 4 of scene 5034407520 , recorded by Landsat 5 on 8 February 1985. Sun angle $21^{\circ}$. Location of Fig.4a and b is shown in upper left.

$\downarrow$ Fig.4. Different representations of rift area on eastern side of Jutulstraumen. North is upwards, parallel with sides, of Fig.4a and $b$.

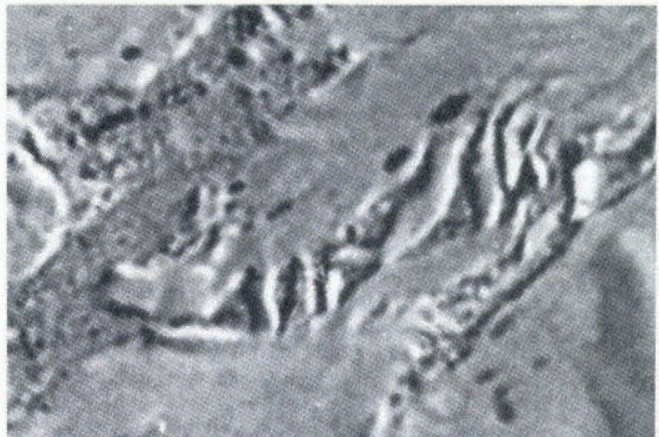

(a) Enlargement to $1: 100000$ of MSS band 4 of part of scene 5034407520. Note poor resolution compared with $4 \mathrm{~b}$.

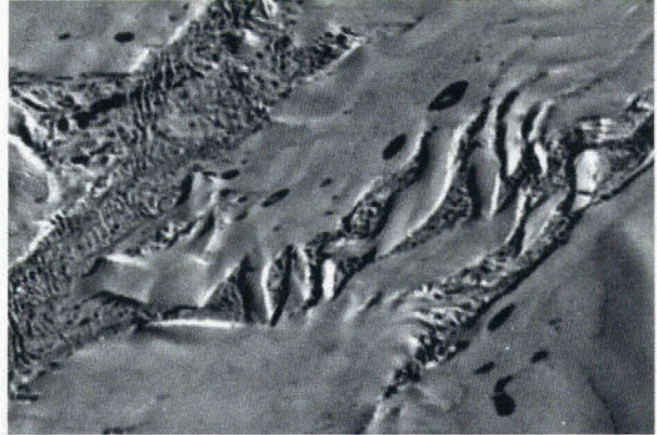

(b) Enlargement to 1:100000 of TM band 4 of the same scene. Note excellent detail, including lakes, and features within the rifts.

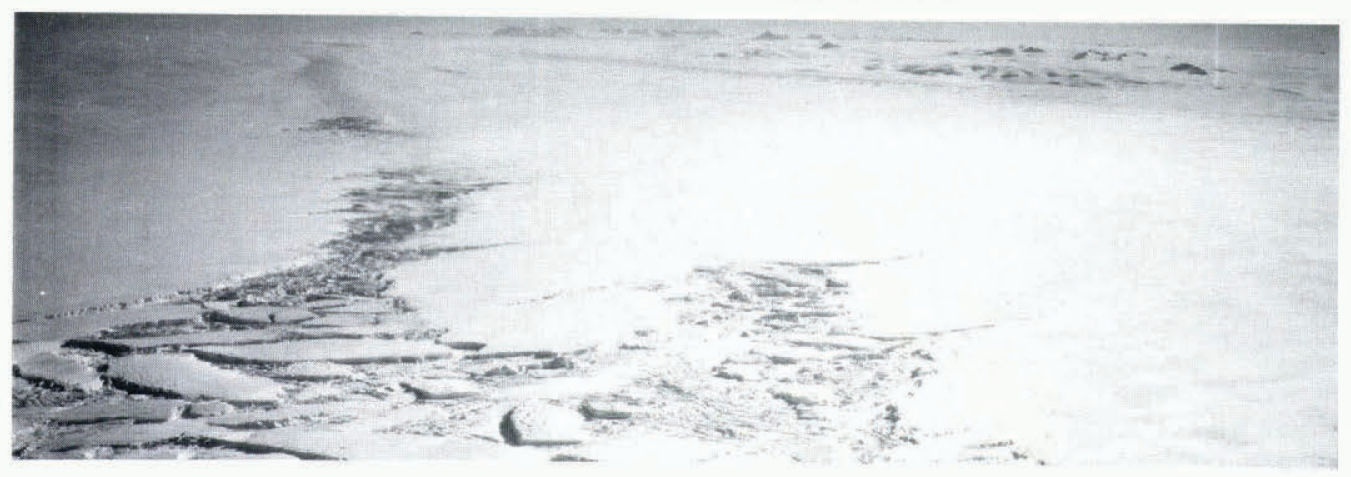

(c) Oblique aerial photograph Nr. 1653 of the same rift area, taken by Norsk Polarinstitutt at 17.40 GMT on 6 January 1959, from $1800 \mathrm{~m}$ altitude, looking south-south-east. We see the rifts on the eastern margin of Jutulstraumen and the mountains behind on both sides of the ice stream. 


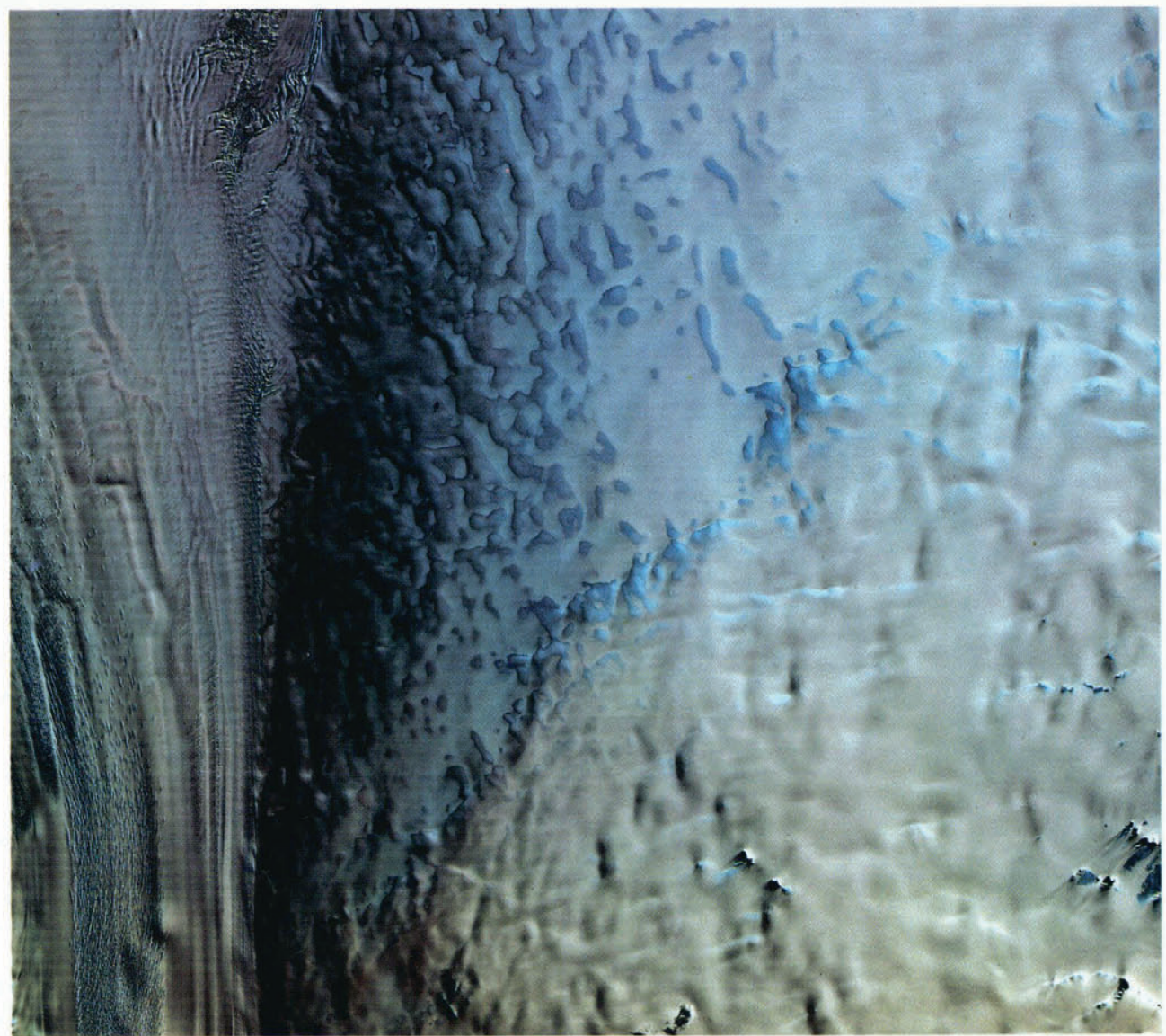

Fig.3. Multi-spectral composite of TM bands 2, 3, and 4 of quadrant 1 of scene 5034407520. Note diagonal blue band across image, reflecting step in bedrock topography. Area to north of step is lower and melting may have occurred. Area to south of line is higher and shows bare blue-ice areas (blue) down-wind of nunataks.

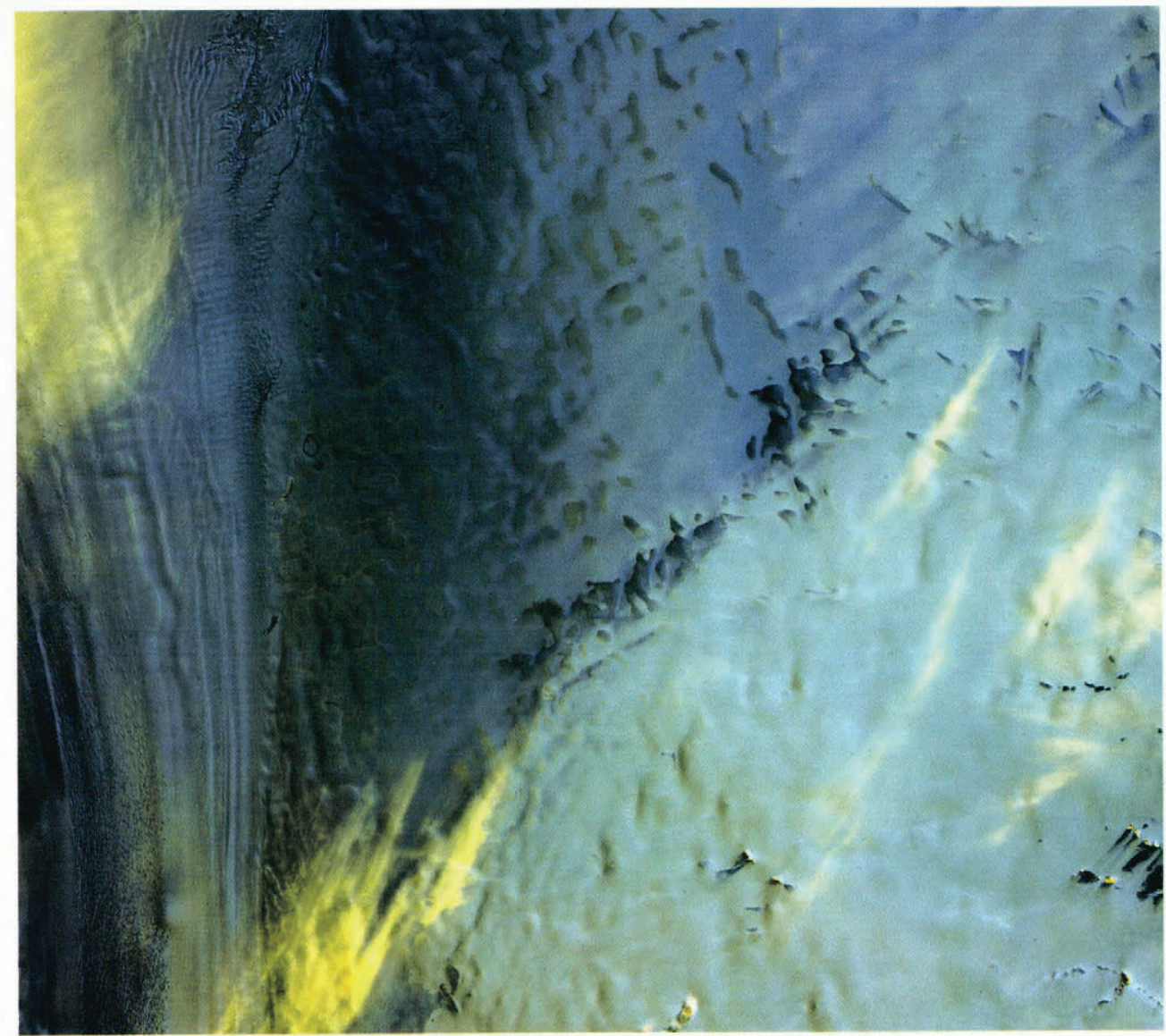

Fig.6. Multi-spectral composite of TM bands 4, 5, and 7 of quadrant 1 of scene 5034407520. Note clouds of high reflectivity (yellow) in the upper left corner, left of lower centre, and as streaks across right part of image. These clouds are transparent in the visible spectral bands (Figs 2 and 3 ). Note also dendritic pattern (faint yellow) running down-slope to Jutulstraumen in the left centre of image. 


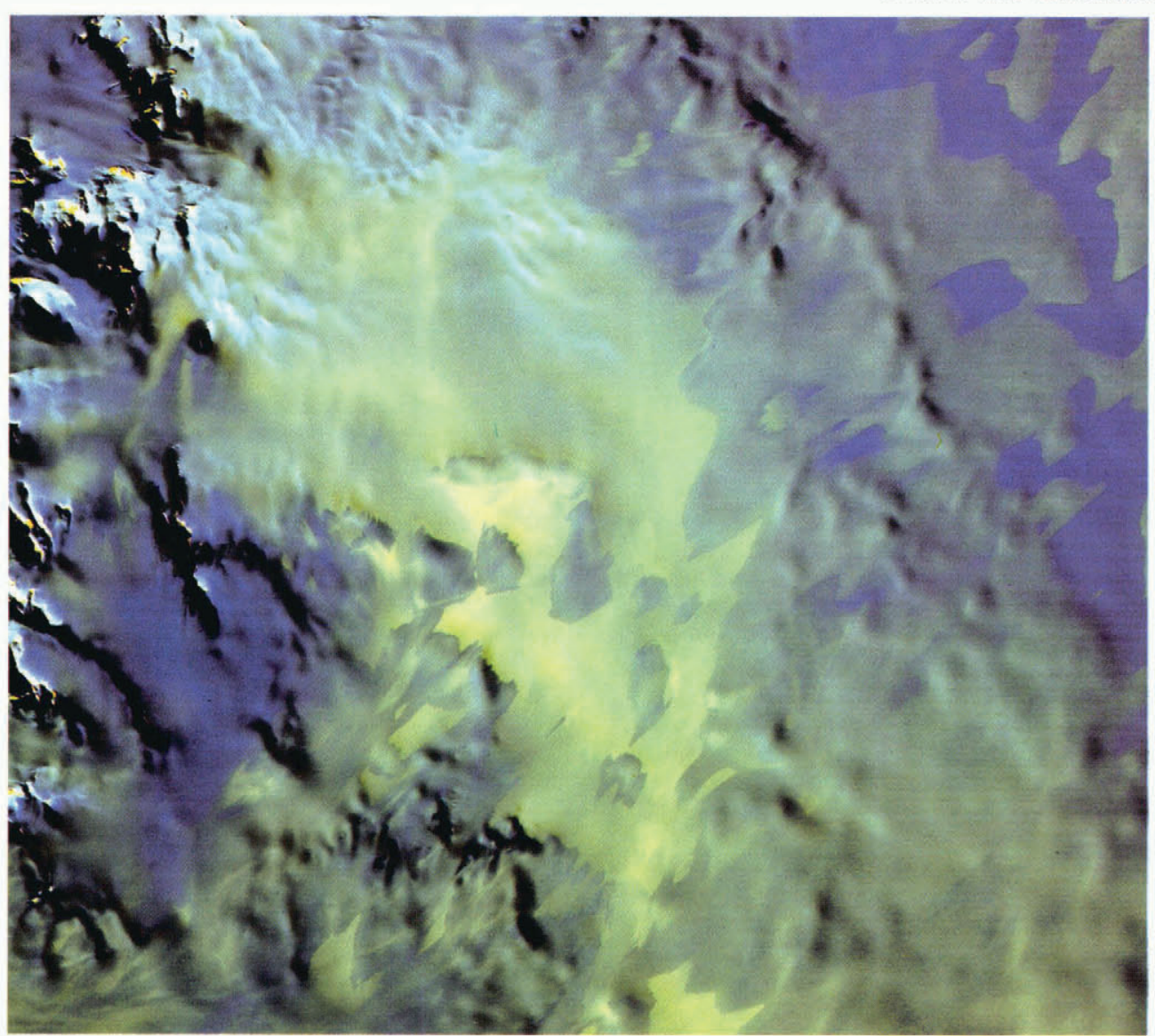

Fig.8. Multi-spectral composite of TM bands 4, 5, and 7 of quadrant 4 of scene 5034407520 . Note the strong patterns in the snow in top right (blue) and centre (yellow) of image. Both show as vague patterns in MSS bands.

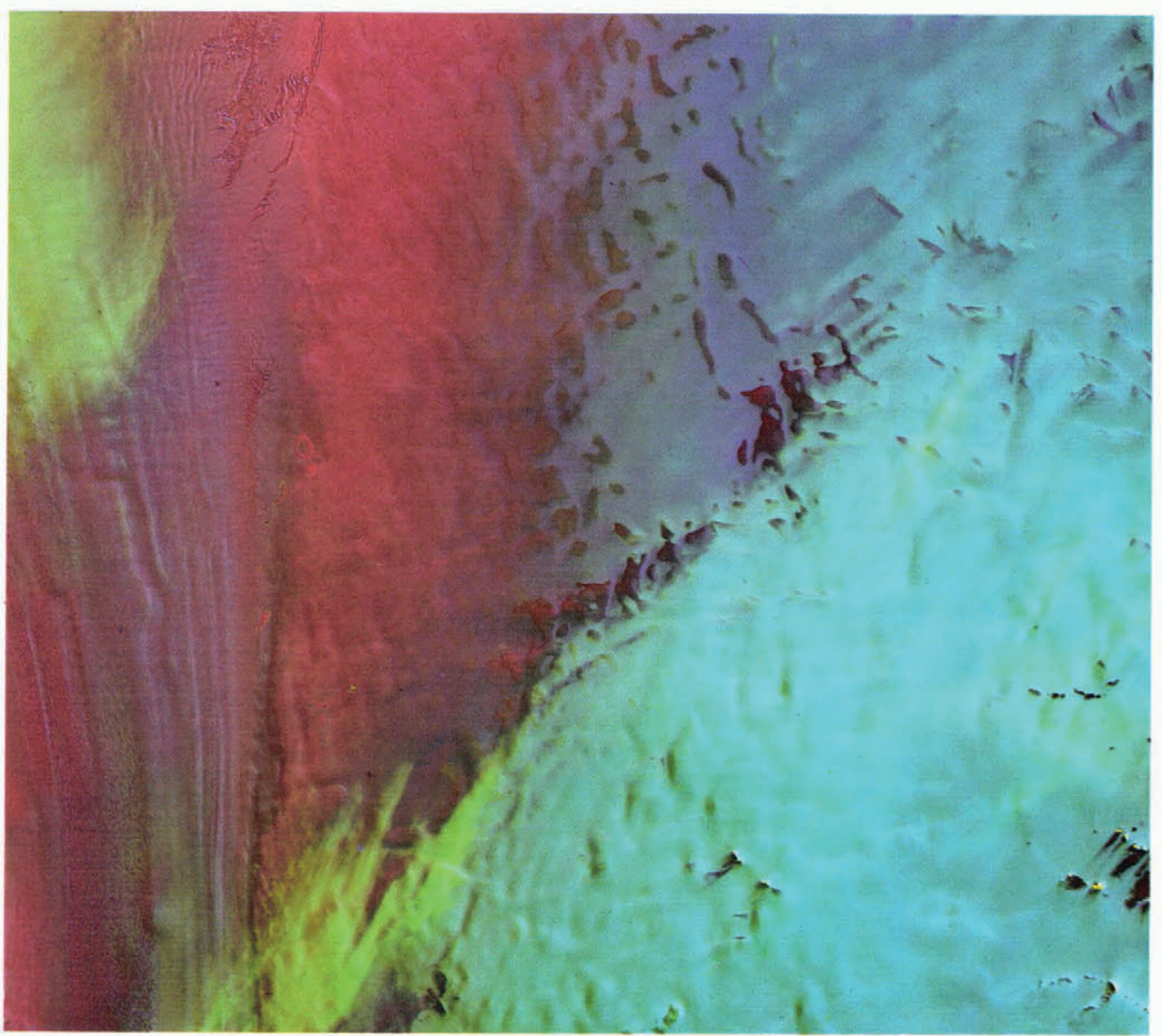

Fig.9. Multi-spectral composite of TM bands 4, 5, and 6 of quadrant 1 of scene 5034407520. Note especially warm areas at lower elevations (red areas in left of picture), and in lakes at the eastern side of Jutulstraumen. Also note high temperatures associated with nunataks in bottom right of picture (orange-yellow), and band of higher temperatures associated with possible "blue-ice" areas crossing picture diagonally. 
fractured areas shown in Fig. 4 lie $20-30 \mathrm{~m}$ deeper than the adjoining broken-off segments of the ice stream. The resolution of MSS images is not adequate for such measurements.

It is well established that the Landsat images also display large-scale snow and ice features that extend over many pixels, such as (paleo)flow lines and sub-surface (bedrock) topography. Such features are shown in Figs 2, 3, and 5. Note especially the continuous flow lines of Jutulstraumen and of smaller glaciers. Note also the eastnorth-east to west-south-west trending "steps" in the subglacial bedrock to the south-east of Jutulstraumen. MSS and TM images depict large features in a similar fashion even though TM images have greater acuity. The reason is that large but subtle features, both on MSS and TM pictures, are enhanced by photometric shading caused by the low Sun angle prevalent in Antarctica.

Our analyses agree with those of Allison and others (1985) in recognizing different types of dark snow and ice signatures in the visible bands. The enhanced composite images (Fig.3) and the individual bands (including the thermal band; see below) show different types of low-albedo features. One of these crosses the image diagonally and is inferred to consist of bare blue ice, which is also warmer than most of the other areas of low albedo (see below). The area north of this diagonal feature is mostly at lower elevations, between 100 and $600 \mathrm{~m}$ where melting may occur, and also shows dark patterns surrounded by snow of lighter signature. The southern area is generally at elevations from 600 to $1200 \mathrm{~m}$. The snow here is lighter, and all lowalbedo areas within the snow and ice are inferred to be bare blue ice, because they generally lie directly down-wind from nunataks and receive less drifting snow. The differ- ences between bare blue ice and other areas of low-albedo ice or snow are better seen in false-colour composites of MSS bands 4,5 , and 7 , or TM bands 2,3 , and 4 , than in the individual bands.

We finally note that the high resolution of TM makes it very attractive for geological and biological studies (e.g. we recognize bird colonies), and for planning field operations to avoid crevassed areas.

\section{TM bands 5 and 7}

\section{(a) Cloud discrimination}

As stated earlier, the images of reflected infra-red light (TM bands 5 and 7) discriminate well between snow and clouds. The differences are illustrated by Figs 2, 3, 5, and 6 . We recognize two types of cloud.

Clouds of the first type are familiar. They are small, dense and low, and cast shadows in the images. They show as a group in the upper central section of Fig.5, and as isolated "dots" to the west of the larger group, and as a group in the lower central section of Fig.6. They seem to be alto-cumulus. Their shadows cause these clouds to be recognized easily, and they show clearly in all spectral bands.

The second type is more enigmatic. These clouds show strongly in TM bands 5 and 7 (Fig.6), but are not seen at all in TM bands $2-4$ (or the MSS bands) (Figs 2 and 3 ). These clouds have similar reflectivities in TM bands 5 and 7 , which suggests that they are ice clouds, because the data of Dozier (1985) show that reflectivity in bands 5 and 7 is high and similar for ice clouds of small crystal radius. That the clouds consist of small ice crystals is also supported by the observation that they are apparently transparent in the

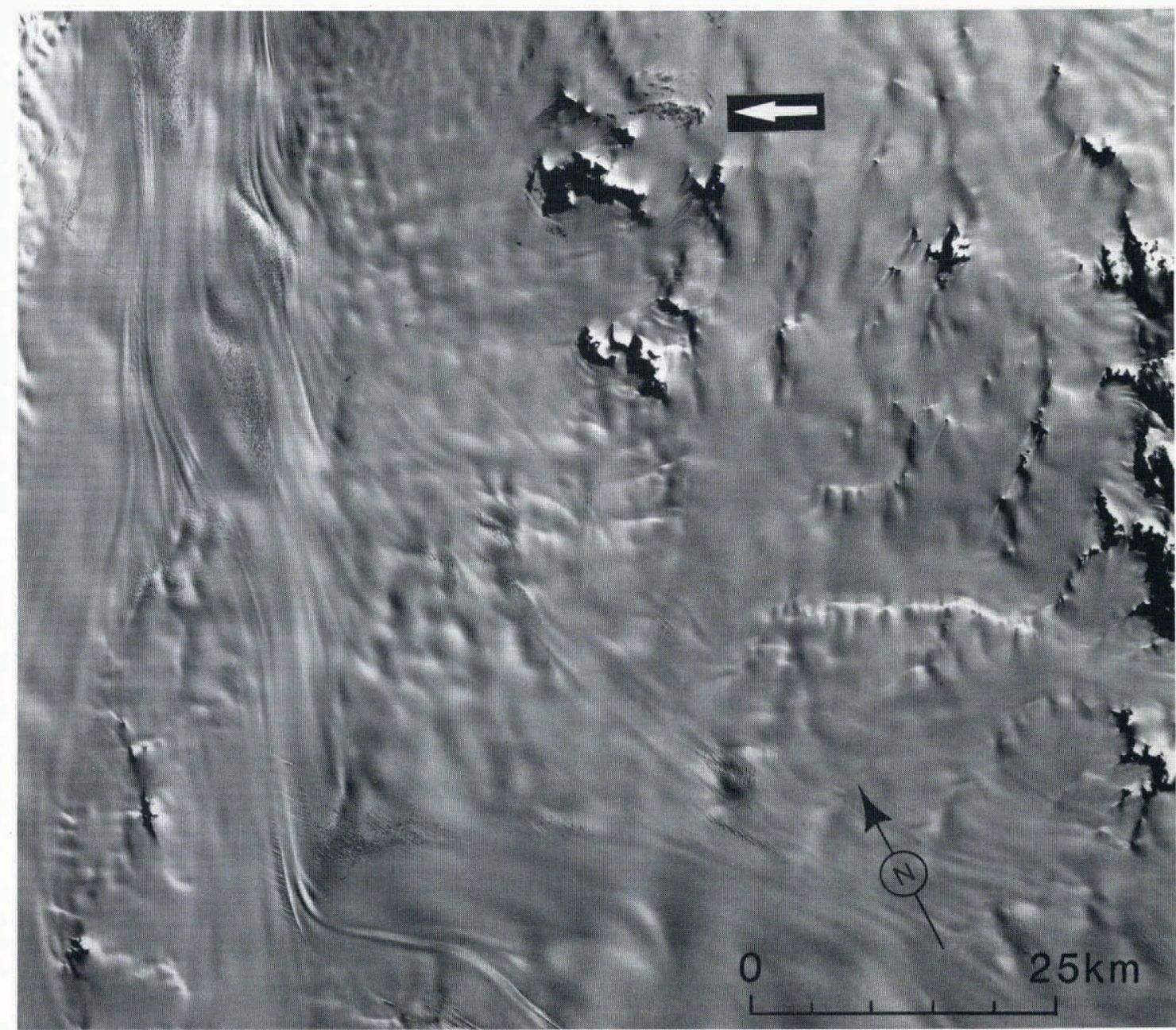

Fig.5. Composite of TM bands 2, 3, and 4 of quadrant 3 of scene 5034407520. The image abuts Fig. 3 on the south and shows the southern continuation from Fig. 3 of Jutulstraumen. Note flow lines entering into the ice stream. Alto-cumulus (?) clouds are seen in the upper centre of the image (arrow). 
visible wavelengths, and that they do not cast shadows. We conclude that these "clouds" are thin (cirrus?), consisting of ice crystals with optical radius $<1 \mu \mathrm{m}$, and that they are probably located at high altitudes.

The lower section of Fig.5 shows additionally a third phenomenon, which may be low clouds or drifts near the surface, because they seem to be affected by topography and surface obstacles in the flow path.

\section{(b) Snow phenomena}

The theoretical considerations referred to earlier indicate that TM bands 5 and 7 should be more sensitive to grain-size variations than the lower bands, with high reflectivities corresponding to snow of small grain-sizes. We believe the images confirm this.

The composite of infra-red reflected bands (Fig.6) supports the conclusion that different types of snow and ice, looking similar in the visual bands, show as different in infra-red reflective bands. The low-albedo feature crossing the image diagonally has similar signature in TM bands 5 and 7 to the blue ice near nunataks, whereas the northern area of low albedo in the visible bands has a different signature of high reflectivity in TM bands 5 and 7.

TM bands 5 and 7 show several snow features not seen in the visible wavelengths. One of these is only seen up-hill of, and near, the melt-water lakes described below. It consists of faint, thin, dendritic patterns running down-hill toward the water (Fig.6); we suggest that these are water courses, which have changed the snow properties. The channels were apparently dry when the image was recorded, because, if wet, they should have shown more conspicuously in the lower bands.

Different and much larger features are seen in the inland snow areas, generally above $2000 \mathrm{~m}$ elevation (Figs 7 and 8). Whereas only faint patterns are visible in TM bands 2-4 (Fig.7), well-developed snow patterns of both relatively high and low albedo are shown in TM bands 5 and 7 (yellow and blue) in Fig.8. The patterns do not show in the thermal band. Examination of a partly overlapping image, recorded 19 days later, shows that the features are persistent. Fig. 8 also shows that the albedo patterns are partly aligned with the prevailing wind direction, which can be inferred from snowdrifts and margins of blue-ice areas down-wind of nunataks (Fig.2). The up-wind side of the patterns appears to have a sharp edge, perhaps of some relief, because it appears to trap material of different reflectivity. The patterns are probably formed by wind and reflect different types of snow.

We conclude that the different reflectivities are most likely related to variations in grain-size, and that the lightest areas show very fine-grained, perhaps new snow, whereas the patterns of lower albedo are caused by coarser snow or possibly glazed surfaces.

The large flow lines on glaciers that appear so clearly in MSS bands and TM bands 2-4 show less clearly in bands 5 and 7. Nor do bands 5 and 7 show bedrock-related topographic features as well as the lower bands. Altogether, the observations support the theoretical principles which suggest that TM bands 2-4 are best for the detection of topographic features owing to photometrically accentuated slopes, whereas TM bands 5 and 7 are best for the detection of clouds and grain-size variations, or other surface properties of snow.

\section{TM band 6}

The thermal band is a useful supplement to the reflective bands. It provides ground-temperature information

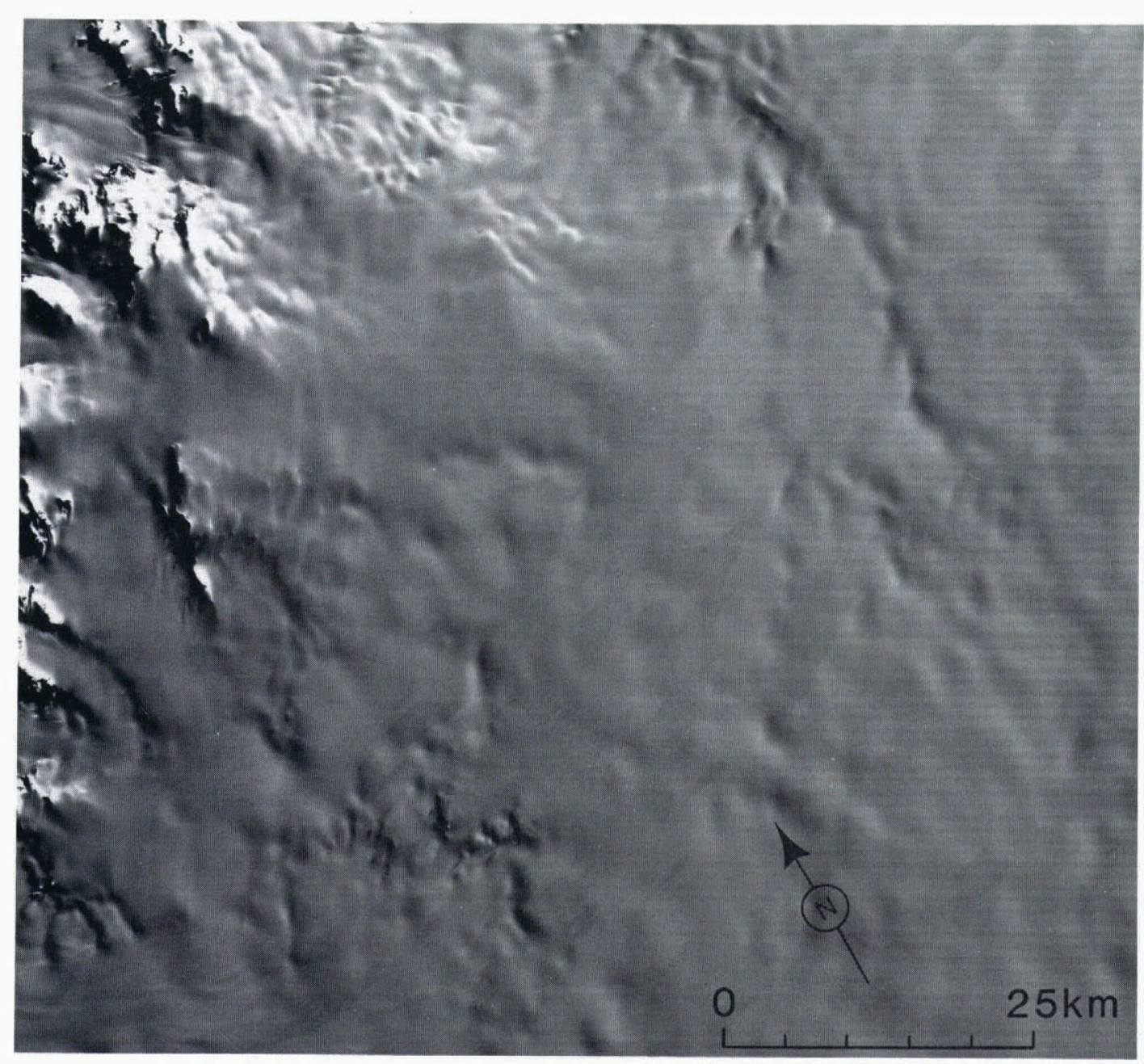

Fig.7. Composite of TM bands 2, 3, and 4 of quadrant 4 of scene 5034407520. Patterns in snow show faintly. 
and, in particular, it shows a strong signal from "warm" bodies within regions of snow and ice. The thermal data can also be used to discriminate between some features that are similar in the reflective bands.

Fig.9 shows a multi-spectral composite including the thermal band (red signature) of quadrant 1. Generally, the temperatures decrease with increasing elevation and are higher on surfaces of low albedo. Jutulstraumen, even though of low elevation, shows relatively low surface temperatures, presumably because cold air follows the topography and flows down along the ice stream. The rifts near the edge of Jutulstraumen show considerably higher temperatures than the surrounding ice, even though the elevation differences are only $20-30 \mathrm{~m}$. This could be caused by increased absorbed solar radiation resulting from multiple reflections within the rifts, and at some locations from the presence of small amounts of water.

Lake-like features are observed both within the rifts,

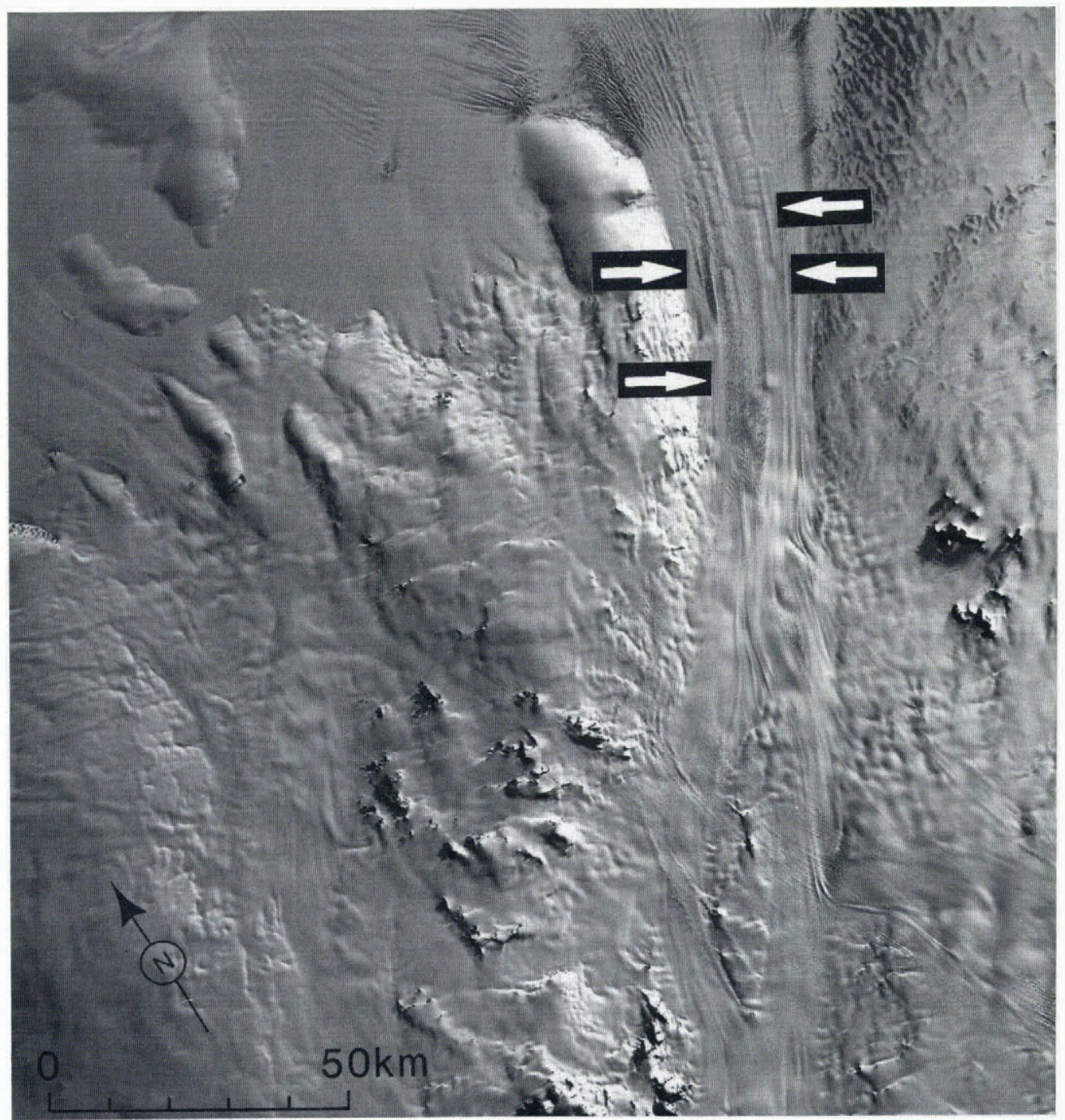

Fig.10. Composite images of MSS bands 4, 5, and 7 of scene 2281-97424, recorded by Landsat 2 on 30 October 1975. Sun angle $22^{\circ}$. Comparison of this image with that from 1985 (Fig.2) reveals a number of both permanent and transitory features. Four stationary ice rumples show in right centre of image, of which the northernmost has a "peak" shape (arrow). These, and the up-stream flow lines, are "permanent", and reflect the bedrock. All rifts and large crevasses are down-stream of these rumples, where the ice is afloat. Note especially the two large crevasses and a deviation in the flow line (arrows). Note also that the low-albedo slopes in the upper part of the comparison images (see Fig.2) cover approximately the same area, and have many identical details, thus demonstrating relationship with topography. The February 1985 image (this figure) shows a more continuous zone of low albedo, presumably because it was recorded at the end of the melt season.

TABLE II

\begin{tabular}{|c|c|c|c|c|}
\hline & \multirow{2}{*}{$\begin{array}{l}\text { Mean } \\
\text { flow rate }\end{array}$} & \multirow{2}{*}{$\begin{array}{l}\text { Standard } \\
\text { deviation }\end{array}$} & \multicolumn{2}{|c|}{ Strain-rate } \\
\hline & & & Longitudinal & Transverse \\
\hline & $\mathrm{m} \mathrm{a}^{-1}$ & $\mathrm{~m} \mathrm{a}^{-1}$ & $10^{-4} \mathrm{a}^{-1}$ & $10^{-4} a^{-1}$ \\
\hline West side $(8)$ & 698 & 22 & 2.9 & \\
\hline East side (14) & 730 & 13 & 0.7 & \\
\hline All localities (22) & 718 & 22 & & 131 (4 sets) \\
\hline
\end{tabular}


along the south-eastern margin of Jutulstraumen, and on the north-west-facing slopes leading down to the ice stream. All of these features have $\approx 0$ albedo in the six reflective bands, indicating the presence of water. The thermal signal shows very high temperatures, probably around $0^{\circ} \mathrm{C}$. We conclude that these are "open" water bodies. The largest of the lakes is seen left of centre in Figs 3 and 9; it is elliptically shaped and $1.5 \mathrm{~km} \times 2 \mathrm{~km}$ in size. Both this and other lakes have a central area covered by snow or ice thick enough to give snow or ice signatures. We do not know from the signatures whether the so-called "open" water is perhaps covered by a very thin layer of ice.

Fig.9 shows relatively high temperatures on blue-ice areas near nunataks and on areas located along a band crossing the image diagonally and located at around $500 \mathrm{~m}$ elevation (compare with Fig.3). Most of the north-westfacing slopes of lower elevation leading down to Jutulstraumen show lower temperatures. This anomaly can be explained if the higher-lying band of higher reflectivity also contains bare blue ice. Thus, the thermal band "flags" the areas of bare blue ice and it helps in discriminating between these and visually similar-looking sites.

\section{Concluding remarks}

The above examples have illustrated the potential of the TM data. Whereas the MSS bands and low TM bands are most useful in recognizing topographic features, enhanced by shading due to low Sun angles, the upper TM bands are best suited to discriminating between properties in snow and ice. Because of limited space, we have discussed only some of the more obvious features. Many more are visible in the TM images but will have to await future discussions.

\section{COMPARISON OF IMAGES OF JUTULSTRAUMEN TAKEN IN 1975 AND 1985}

More than a decade has now passed since the first Landsat data were collected from Antarctica. These early images form an important basic data set, which can be especially valuable because of the remoteness of the Antarctic continent, the difficulties of access, and the expenses of field work. We therefore examined whether repeated Landsat images can be used to provide quantitative glaciological data. A similar study was conducted by Lucchitta and Ferguson (1986).

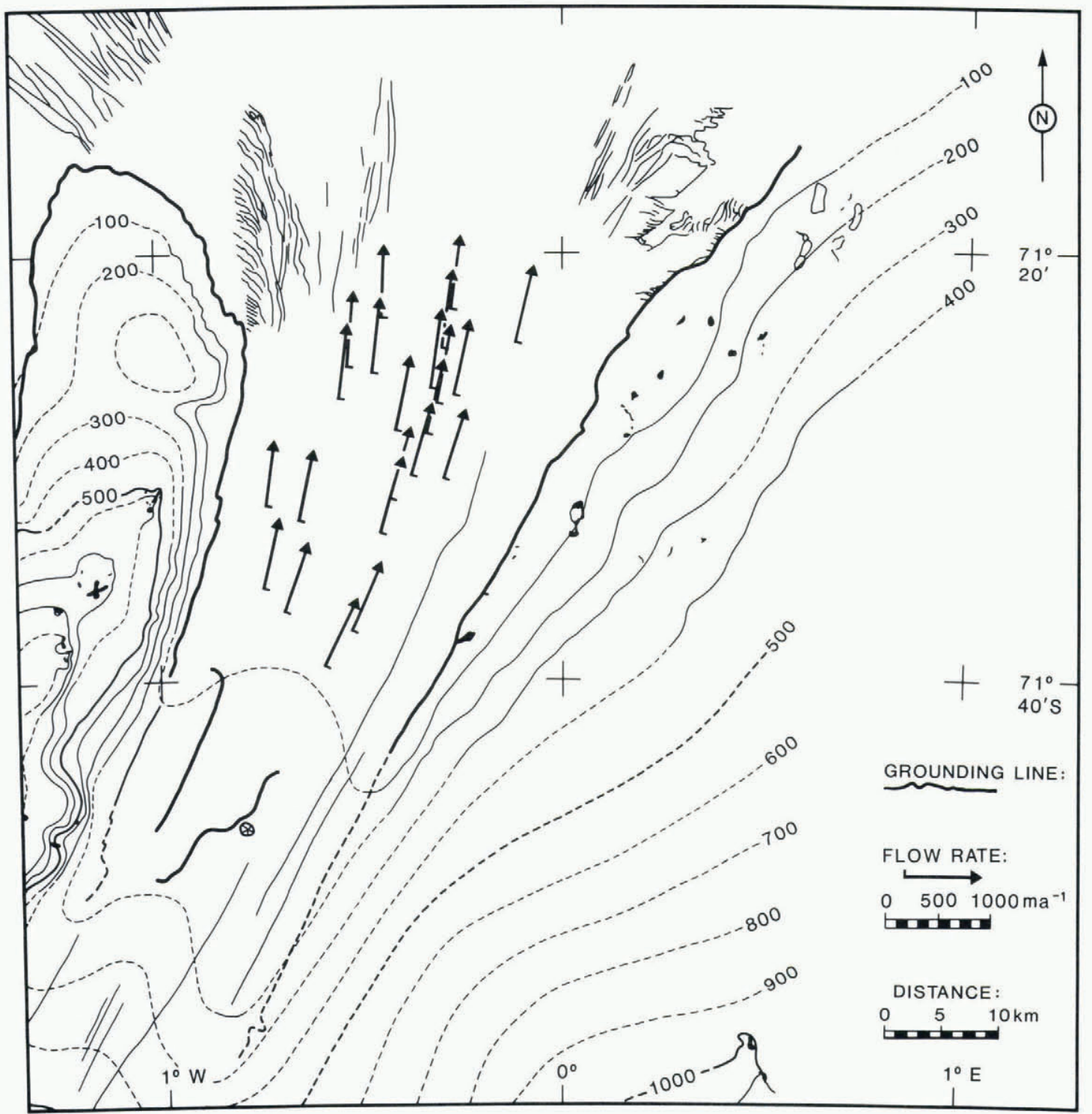

Fig.11. Map of displacements of features recognized in the two images of Jutulstraumen (Figs 2 and 10) recorded 9.3 years apart. The arrows show flow rates determined from 22 points recognized in both images. The elevation contours are based on Norsk Polarinstitutt surveys and are shown dashed where they are approximate. Lakes are shown as solid black. Zones of definite grounding within the ice stream and near the $100 \mathrm{~m}$ contour are also shown. The flotation line is probably located down-stream of this contour. 
Fig.10 shows the enhanced MSS image recorded on 30 October 1975. Altogether 22 point features, moving with the glacier and mostly located at the edges of large crevasses, have been identified in this image. These features are also visible in the image of 8 February 1985 (Fig.2), and remain recognizable, even though subdued by snow accumulation, because they are located where crevasses are few and distinct. Fig.11 shows the displacements and corresponding flow rates that could be measured from the distinctive features on the two images, acquired at an interval of 9.3 years.

The flow rates are surprisingly similar. Table II shows the results for all points, divided into two groups. Of the two groups, the eight points on the west side of Jutulstraumen are closer to the edge and have generally lower velocities. The point closest to the edge shows the lowest flow rate at $649 \mathrm{~m} \mathrm{a}^{-1}$. The 14 points on the east side have generally higher flow rates, with a maximum of $744 \mathrm{~m} \mathrm{a}^{-1}$.

A flow rate of $0.72 \mathrm{~km} \mathrm{a}^{-1}$ agrees well with maximum flow rates of $0.39 \mathrm{~km} \mathrm{a}^{-1}$, measured $\approx 90 \mathrm{~km}$ up-stream at $900 \mathrm{~m}$ elevation (Gjessing 1972), and a rate of $\approx 2 \mathrm{~km} \mathrm{a}^{-1}$ at the ice front that we have determined from repeated surveys.

The main errors in the flow-rate determinations result from poor geometric accuracy in the 1975 image, and from imprecise positioning of points caused by uncertainties in identifying identical details of the features in the two images. Geometric inaccuracies were partly removed by manually adjusting the 1975 and 1985 images to fixed points, but some errors remain. We had expected the positioning of the points to be more difficult and to lead to larger scatter in the results than observed. The relatively good agreement in the measurements indicates that the technique works well in spite of potential difficulties. We believe that the standard deviations (Table II) give a good estimate of the likely error in the mean flow rates.

The mean flow rates increase from the edge to the centre, and also down-stream, and are thus consistent with glaciological principles. However, comparison of individual points shows that the down-stream changes in flow rates are too small and irregular to allow a rigorous strain analysis involving all individual points. Instead, Table II shows the mean strains along, and transverse to, the flow.

The longitudinal surface strain is calculated from the mean change in flow rate between the up-stream and the down-stream group of points on each side of the centre line. The change in flow rates is only $8 \mathrm{~m} \mathrm{a}^{-1}$ on the west side and $2 \mathrm{~m} \mathrm{a}^{-1}$ on the east side, over distances $>20 \mathrm{~km}$, corresponding to only a small acceleration along this section of the ice stream.

The transverse strains have been determined at $90^{\circ}$ to the flow direction, by measuring the change in distance between pairs of points moving coherently in longitudinal direction. It varies for four sets between 113 and $162 \times$ $10^{-4} \mathrm{a}^{-1}$. Thus the transverse strain is two orders of magnitude larger than the strain along the flow direction. This large difference results from the widening of the ice stream over this section.

Figs 2 and 10 show the fractures resulting from the high transverse strains, and indicate in addition that larger longitudinal strains occur further down-stream.

It was not possible to define the flotation (grounding) line within Jutulstraumen with confidence even on enhanced false-colour composite TM image at maximum enlargement. Fig.11 shows locations of grounded ice, which are identified either by bedrock topography, which shows as a stationary feature, or by stationary crevasse patterns. The actual grounding line is an unknown distance down-stream from these places. Also shown is the $100 \mathrm{~m}$ contour line from Norsk Polarinstitutt 1:250000 map sheet G5, Ahlmannryggen. This contour is approximate. It seems likely, from comparison with similar ice streams, that the flotation line should be close to, and down-stream of, the $100 \mathrm{~m}$ elevation.

There is an intriguing aspect of the crevasses which may be related to the position of the grounding line. Fig. 10 shows two large crevasses, in the western and central part of Jutulstraumen, located about 20 and $30 \mathrm{~km}$ respectively from a stationary "ice peak" farther south, and a deviation in the flow line at $20 \mathrm{~km}$. Fig. 2 shows that these three features have moved about $7 \mathrm{~km}$ down-stream, and that no new large crevasses have formed in the former positions. This suggests that these features were caused by singular events, rather than by a permanent aspect of the strain regime such as would be related to topography. One such event that could have caused the flow deviation would have been a small surge from a tributary glacier. However, we consider it more likely that these features are related to a change in flow regime brought about by a major calving on the ice-shelf front.

The distance from these features to the seaward edge is presently nearly $200 \mathrm{~km}$. The ice shelf was, however, formerly even larger, and extended as a $50 \mathrm{~km}$ wide, $100 \mathrm{~km}$ long ice tongue, named Trolltunga. This tongue calved off in July 1967 (Vinje 1977). Calving could have changed the stress regime, causing an acceleration of the inland ice shelf and the two large crevasses.

No field data are available to evaluate how the calving may have changed the flow regime of the ice shelf. But a simple calculation can test the explanation. In the October 1975 image, the deviation in flow line and the large crevasses are respectively $7.4,7.5$, and $16.5 \mathrm{~km}$ down-stream from the $100 \mathrm{~m}$ contour, which translates into a time span of $10.1,10.5$, and 22.2 years considering the flow rates at each locality. The image was recorded 8.3 years after Trolltunga calved. Thus the intervals match well for two of the large features if the flotation line was near, and downstream of, the $100 \mathrm{~m}$ contour at the time of calving. If this explanation is correct, then this also implies that the stress and the acceleration must have propagated rapidly across the ice shelf.

\section{ACKNOWLEDGEMENTS}

We gratefully acknowledge much help from colleagues at Norsk Polarinstitutt and at US Geological Survey, Flagstaff. Image 5034407520 was reproduced by permission of EOSAT.

\section{REFERENCES}

Allison I, Young N W, Medhurst T 1985 Correspondence, On re-assessment of the mass balance of the Lambert Glacier drainage basin, Antarctica. Journal of Glaciology 31(109): 378-381

Choudhury B J, Chang A T C 1981 On the angular variation of solar reflectance of snow. Journal of Geophysical Research 86(C1): 465-472

Colwell R N (ed) 1983 Manual of remote sensing. Second edition. Falls Church, VA, American Society of Photogrammetry

Dozier J 1985 Snow reflectance from thematic mapper. Landsat-4 science characterization early results. Vol IV. Applications. Washington, DC, National Aeronautics and Space Administration: $349-357$ (NASA Conference Publication 2355)

Gjessing Y T 1972 Mass transport of Jutulstraumen ice stream in Dronning Maud Land. Norsk Polarinstitutt. Arbok 1970: 227-232

Hall D K, Martinec J 1985 Remote sensing of ice and snow. London and New York, Chapman and Hall

Lucchitta B K, Ferguson H M 1986 Antarctica: measuring glacier velocity from satellite images. Science 234(4780): $1105-1108$

Lucchitta B K, Eliason E M, Southworth S 1985 Multispectral digital mapping of Antarctica with Landsat images. Antarctic Journal of the United States 19(5): 249-250

Ødegaard H, Helle S G 1982 Polar mapping using Landsat data. Final report. Oslo, IBM and Norsk Polarinstitutt

Orheim O 1978 Glaciological studies by Landsat imagery of perimeter of Dronning Maud Land, Antarctica. Norsk Polarinstitutt. Skrifter 169: 69-80

Qunzhu Z, Meisheng C, Xuezhi F, Fengxian L, Xianzhang C, Wenkun S 1984 Study on spectral reflection characteristics of snow, ice and water of northwest China. Scientia Sinica Ser B 27(6): 647-656

Vinje T E 1977 Drift av Trolltunga i Weddellhavet. Norsk Polarinstitutt. Arbok 1975: 213 